\title{
Reforma y disciplina financiera en estados y municipios
}

Reform and Financial discipline in the States and Municipalities

Resumen

El presente documento destaca algunas de las principales causas del crecimiento del endeudamiento público estatal que se ha observado en México durante los últimos años. Estas causas se refieren, principalmente a la crisis económica mundial (iniciada en 2008), a la insuficiencia en la generación de recursos propios por parte de las Entidades Federativas y Municipios y al creciente gasto descentralizado en salud y educación. A fin de afrontar los posibles peligros que el mayor endeudamiento público podría acarrear a la economía en su conjunto, el Congreso de la Unión presentó y aprobó una iniciativa de Reforma en Materia de Disciplina Financiera en Estados y Municipios, que otorga entre otras cosas, mayores facultades a la Cámara de Diputados para legislar en esta materia, imponer límites al endeudamiento subnacional, así como conocer y objetar sobre las estrategias de reducción del endeudamiento de cada una de las Entidades Federativas. Si bien estos límites posiblemente cumplan con su cometido de hacer parecer las finanzas públicas subnacionales más "sanas", lo cierto es que la reforma no ataca el principal problema de las finanzas públicas estatales y municipales, que es la escasa generación de ingresos propios.

\section{Palabras clave:}

- Política fiscal

- Sector Público

- Gasto Público

\section{Abstract}

The present document emphasizes some of the main causes of the growth of state public indebtedness that has been observed in Mexico during the past few years. These causes are mainly referred to the world-wide economic crisis (in 2008), the insufficient generation of own resources on the part of Mexican States and Municipalities and to the increasing expenditures on decentralized health and education. In order to confront the possible dangers that the greater public indebtedness could carry to the economy as a whole, the Mexican Congress presented and approved an act which reforms the law in the matter of Financial Discipline in States and Municipalities, that grants among other things, greater faculties to the House of Representatives to legislate in this matter, to impose limits to the subnational indebtedness, as well as to know and to object on the strategies of reduction of the indebtedness of each one of the States. Although, these limits possibly make subnational public finances seem "healthy", they do not face the problem the main problem of the state and municipal public finances, that is, its inefficient taxation

\section{Keywords: \\ - Fiscal Policy \\ - Public Sector \\ - Public expenditure}

Desde 2011 se ha presentado un intenso debate en torno a la forma en que debería atenderse el problema del creciente endeudamiento público de las entidades federativas y municipios del país. Lo anterior debido a que a partir

\footnotetext{
* Doctor en Economía por la UNAM, y ha trabajado temas relacionados con el financiamiento para el desarrollo, en específico, en torno a la relación entre desarrollo financiero y crecimiento económico. Actualmente es profesor tanto de la División de Estudios Profesionales como de la División de Estudios de Posgrado de la Facultad de Economía de la UNAM, e investigador en la Dirección de Estudios Macroeconómicos del Centro de Estudios de las Finanzas Públicas de la Cámara de Diputados: luisclmiller@gmail.com, jose.clavellina@congreso.gob.mx.
} 
de la crisis económica internacional, los ingresos nacionales y estatales se vieron afectados y los estados se vieron en la necesidad de recurrir al endeudamiento para hacer frente a sus necesidades de gasto e inversión pública. El problema adquirió especial relevancia pues en el período 2008-2012 la deuda pública estatal y municipal se duplicó en términos nominales.

\section{Endeudamiento estatal y municipal en México}

De acuerdo con datos de la Secretaría de Hacienda y Crédito Público (SHCP), en términos nominales, la deuda pública de estados y municipios pasó de 90.7 mil millones de pesos en 2000 a 106.1 mil millones en 2006 y a 434.8 mil millones al cierre de 2012; mientras que en términos reales, de 2002 a 2007 la tasa de crecimiento anual de la deuda estatal se ubicó en $6 \%$ y de 2008 a 2012 ésta fue de 16 por ciento.

\section{Gráfica 1}

Saldo de las obligaciones financieras de entidades federativas y municipios

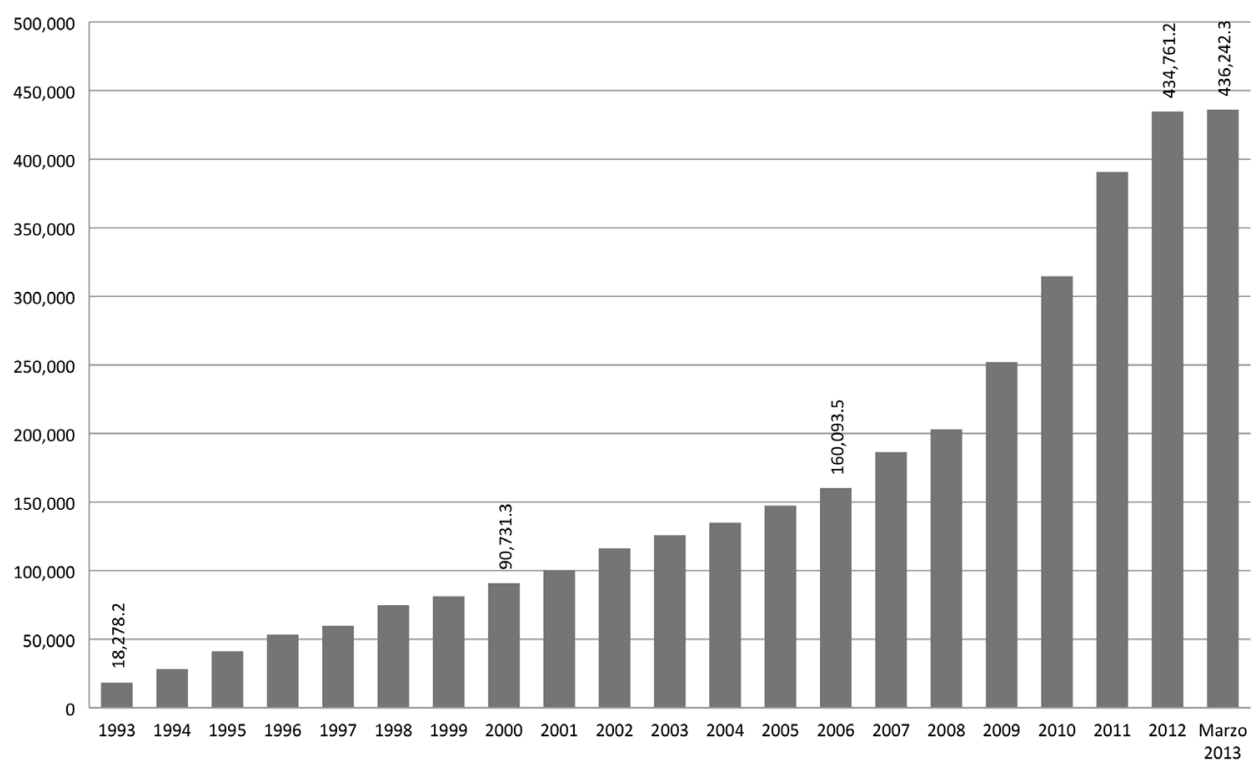


Entre algunos de los datos del comportamiento de la deuda estatal y municipal se encuentran los siguientes:

- A diciembre de 2012, el saldo de la deuda estatal y municipal representó $2.9 \%$ del PIB.

- Del total de deuda de las entidades al cierre de 2012, 61.4\% correspondió a obligaciones con la banca comercial, 20.6\% a obligaciones con la banca de desarrollo, $15 \%$ a bursatilizaciones, $1.8 \%$ a fideicomisos y $1.2 \%$ a otras obligaciones financieras.

- En 2012 la deuda de los estados promedió 86.1\% de las Participaciones Federales.

Cabe señalar que el nivel de la deuda se mantiene todavía en niveles controlables y que el problema de deuda no es generalizado, pues en 2012 fueron 13 los estados que concentraron $82 \%$ del total de la deuda subnacional.

$\mathrm{Al}$ primer trimestre de 2013, el saldo total de la deuda de estados y municipios fue de 436.2 miles de millones de pesos, lo que representó $2.7 \%$ del PIB; este porcentaje fue ligeramente menor al del 2012, no obstante se encuentra 1.0 punto porcentual del PIB por encima de lo que ocurría antes de la crisis.

\section{Gráfica 2}

\section{Deuda de entidades federativas y municipios}

(Saldo como porcentaje del PIB)

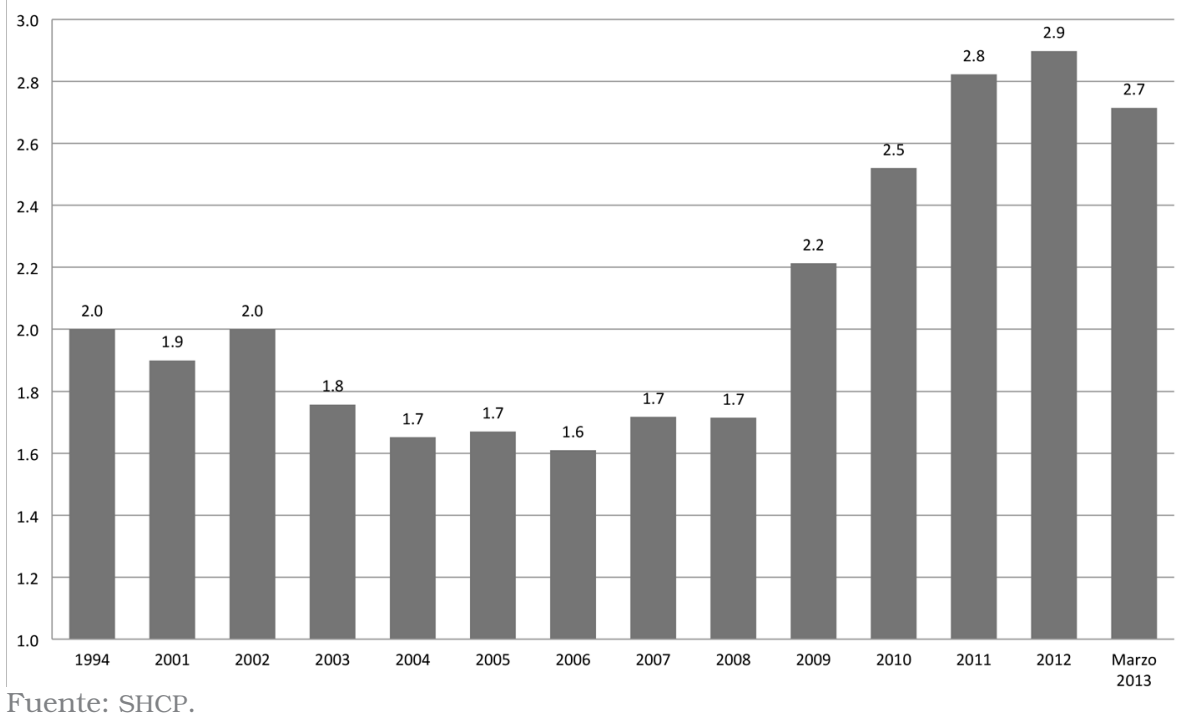


De igual forma, al primer trimestre de 2013, el saldo de la deuda de estados y municipios representó $81.5 \%$ respecto de las participaciones federales. Esto es, 4.6 puntos porcentuales menos respecto el cierre de 2012. Sin embargo, también es importante indicar que comparado con lo ocurrido en 2008, el indicador de 2013 es 30.8 puntos porcentuales superior, lo que da cuenta de que los ingresos por participaciones estaban siendo comprometidos en un porcentaje cada vez mayor al pago de empréstitos y que fue a partir de la crisis que dicho endeudamiento comenzó a exacerbarse.

\section{Gráfica 3}

\section{Deuda de entidades federativas y municipios}

(Saldo respecto de las participaciones federales)

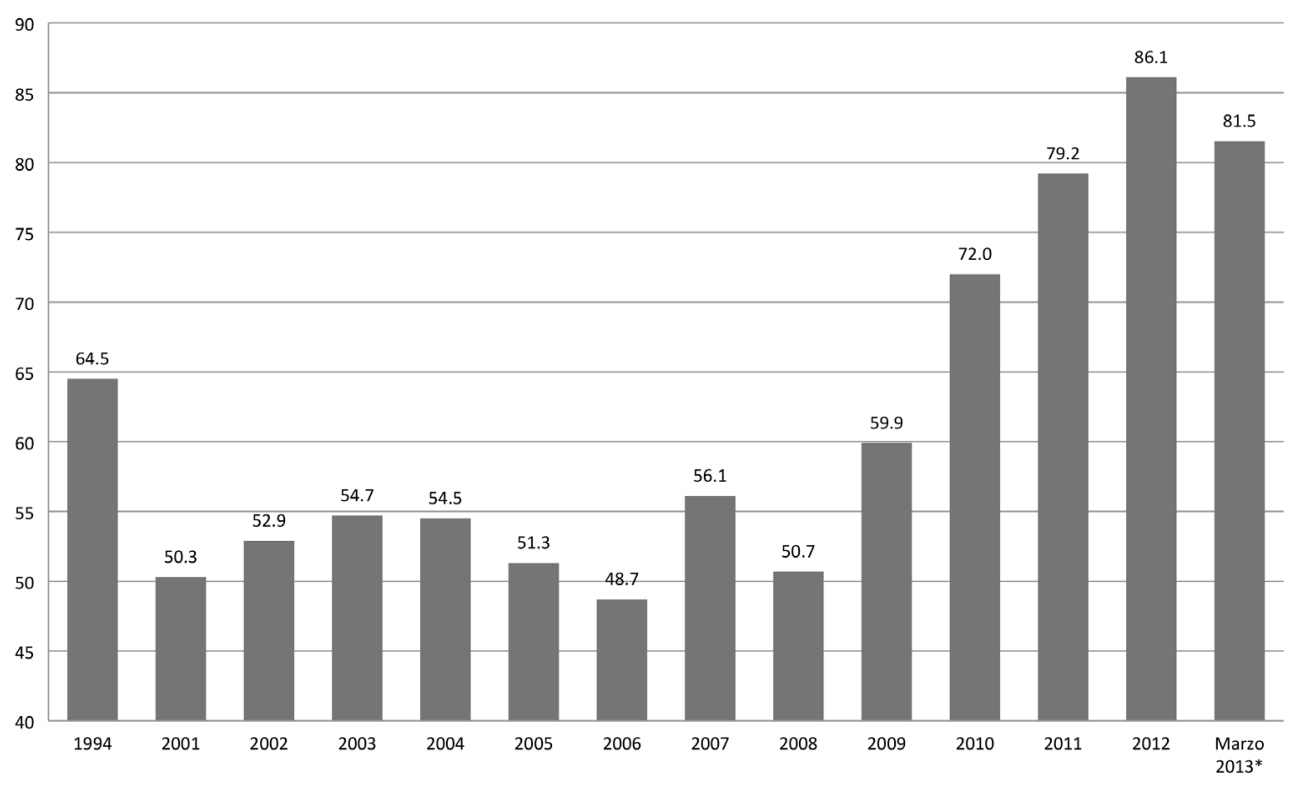

Fuente: SHCP.

En lo que se refiere al plazo promedio de vencimiento, al primer trimestre de 2013 éste se ubicó en 15.4 años. Lo anterior está ligeramente por debajo de los 16.0 años en que se encontraba al cierre de 2012, pero se trata de un plazo considerablemente mayor al de los 3.2 años del promedio observado en 2008. 


\section{Gráfica 4}

\section{Deuda de entidades federativas y municipios}

(Saldo respecto de las participaciones federales)

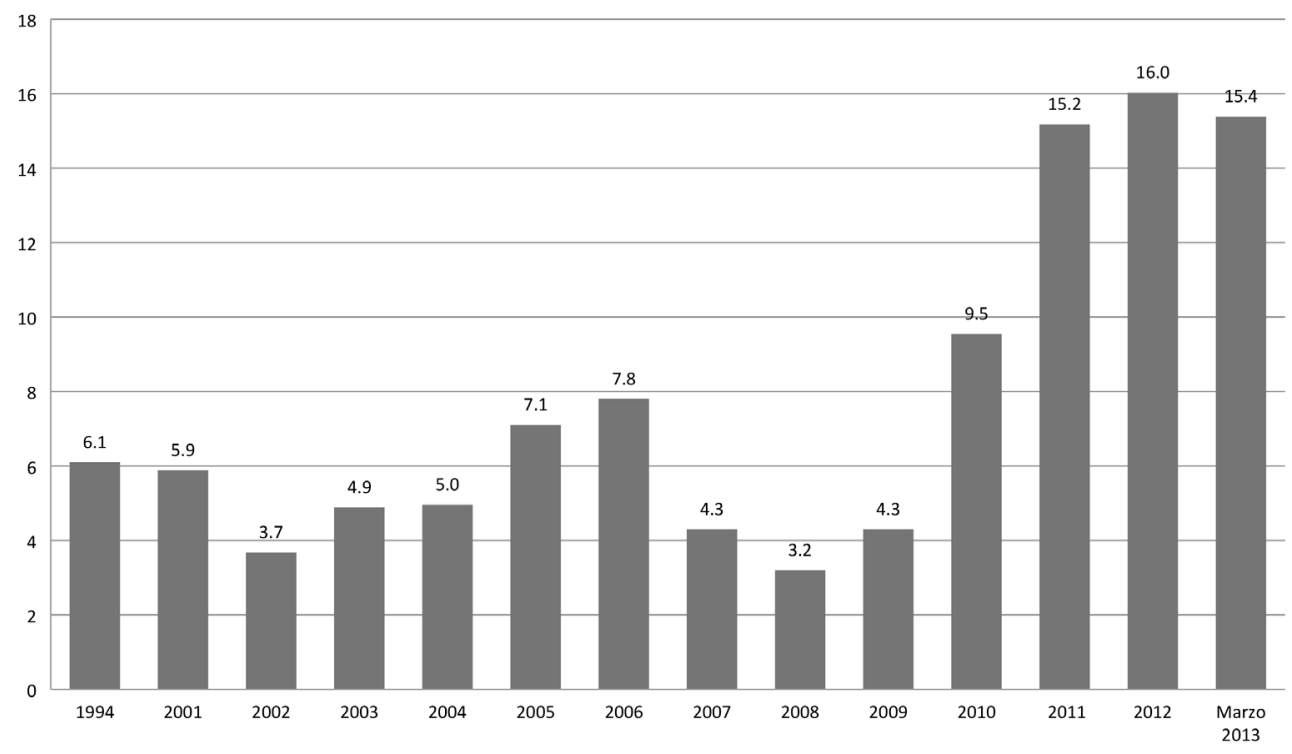

Fuente: SHCP.

La extensión de los plazos, como se verá más adelante, es también una de las causas por las que los gobiernos subnacionales han incrementado su endeudamiento. Esto es, la deuda se hizo cada vez más atractiva porque los plazos, montos y costos se dieron en mejores condiciones para su contratación.

En lo que se refiere a los costos, al primer trimestre de 2013, la tasa de interés promedio fue $6.5 \%$. En este caso el promedio se ubicó en el mismo nivel del cierre de 2012 y 3.1 puntos porcentuales por debajo de la tasa reportada en 2008. 


\section{Gráfica 5}

\section{Costo promedio ponderado por entidad federativa}



Fuente: SHCP.

Hasta aquí puede verse que si bien el endeudamiento público de las entidades federativas efectivamente ha aumentado, los plazos y las tasas promedio también han resultado ser menores a las que se observaban antes de la crisis mundial.

Conviene indicar que cada uno de los estados de la República observa una realidad distinta en cuanto a la situación de su endeudamiento. En términos de montos, las entidades con un mayor endeudamiento son el Distrito Federal, Nuevo León y el Estado de México. En tanto que los estados menos endeudados son Tlaxcala, Campeche y Querétaro.

Lo anterior no quiere decir que, en el caso de los estados con mayor nivel de deuda, la situación necesariamente represente un peligro, pues se trata de las entidades que más contribuyen al PIB y donde se recaudan más impuestos.

También es importante recordar, que los estados menos endeudados no reflejan un mejor manejo de sus finanzas públicas, pues es bien sabido que el adecuado uso del endeudamiento permite realizar obras de infraestructura y proyectos sociales y productivos que elevan la productividad y compe- 
titividad de diversos sectores económicos en el presente y en beneficio tanto de las generaciones actuales como las futuras.

\section{Obligaciones financieras de estados y municipios} marzo de 2013

(millones de pesos)

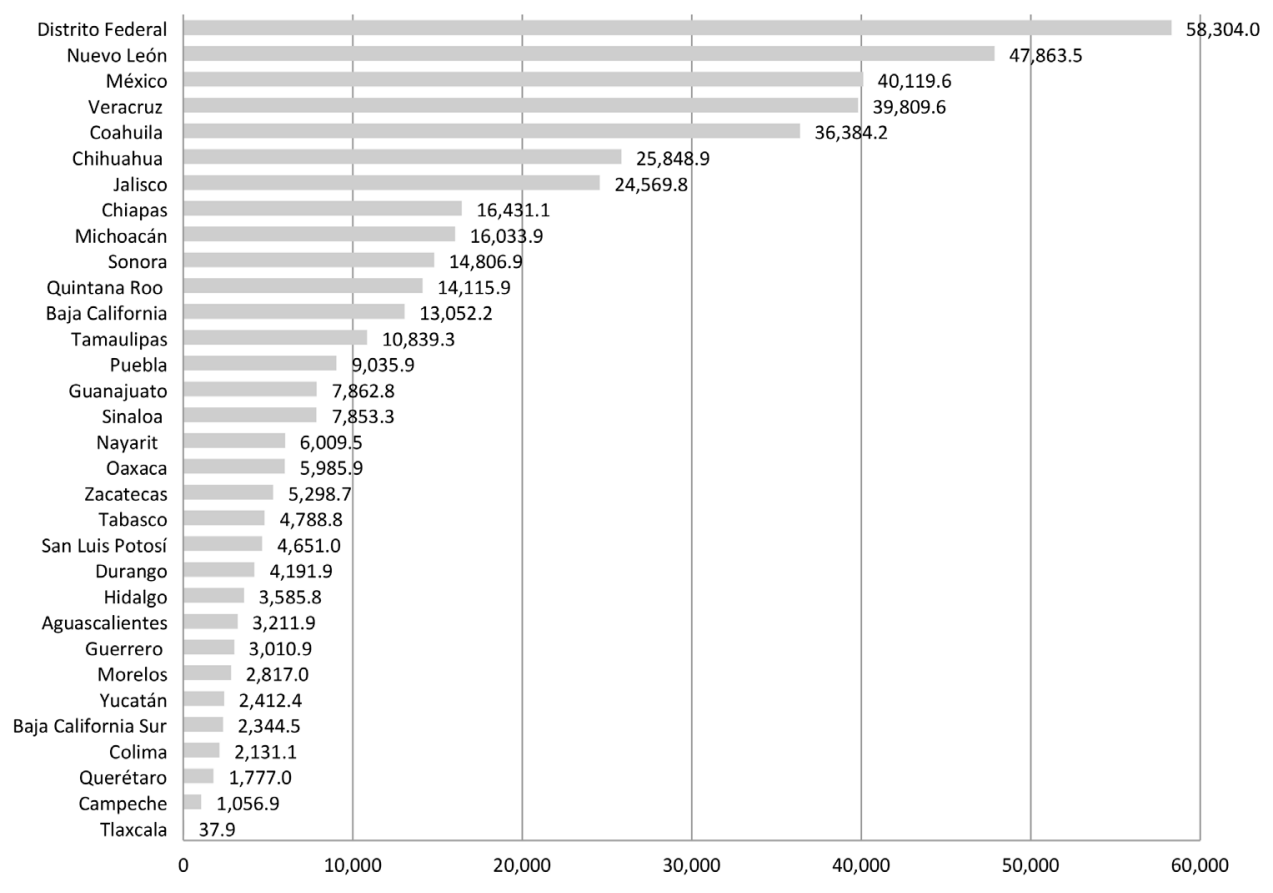

Fuente: SHCP.

Si tomamos como referente el endeudamiento como proporción del PIB de cada estado, las entidades con mayor nivel de endeudamiento serían Coahuila, Nayarit y Quintana Roo. En tanto que las menos endeudadas corresponden nuevamente a Tlaxcala, Campeche y Querétaro. 


\section{Gráfica 7 \\ Obligaciones financieras de estados y municipios \\ como proporción del PIB, marzo de 2013}

(porcentajes)

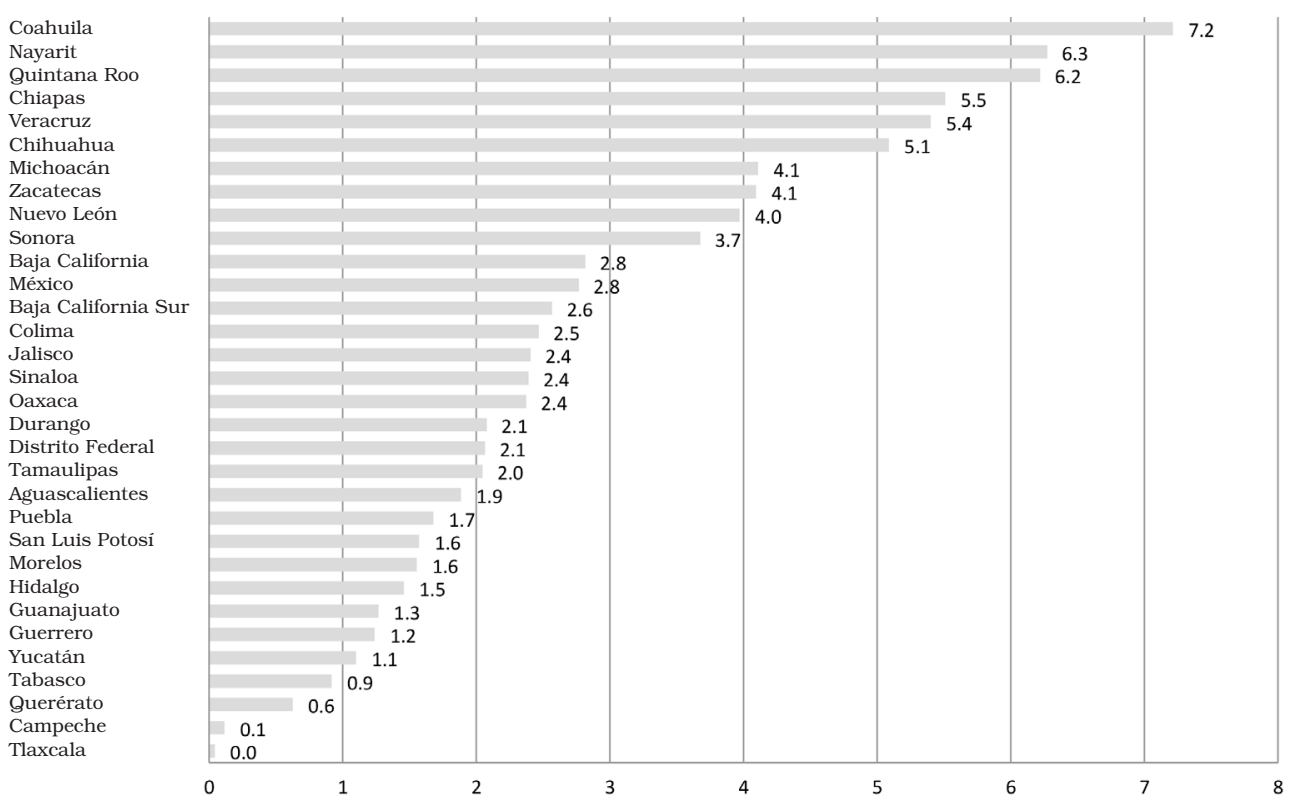

Fuente: SHCP.

Es preciso indicar que en la información que aquí se presenta no se trata de un estudio del endeudamiento de cada entidad. El análisis del endeudamiento de cada Estado debe tener en consideración además del monto del endeudamiento una serie de elementos tales como la capacidad de generar ingresos propios, los plazos, los costos, el destino del endeudamiento, y el si los recursos van a permitir generar un flujo de ingresos futuro que permita pagar parte o la totalidad del financiamiento. Por lo que es pertinente aclarar que no se está calificando el nivel de deuda de cada estado, sino que se presenta únicamente la posición en que se encuentra a nivel nacional.

Por otro lado, si se toma en cuenta el endeudamiento estatal como proporción de las participaciones federales, los estados con mayor nivel de deuda serían: Coahuila, Quintana Roo y Nuevo León, con porcentajes que superan $200 \%$. Las entidades con menor deuda vuelven a corresponder a Tlaxcala, Campeche y Querétaro. 


\section{Gráfica 8}

Obligaciones financieras de estados y municipios como proporción de participaciones federales, marzo de 2013

(porcentajes)
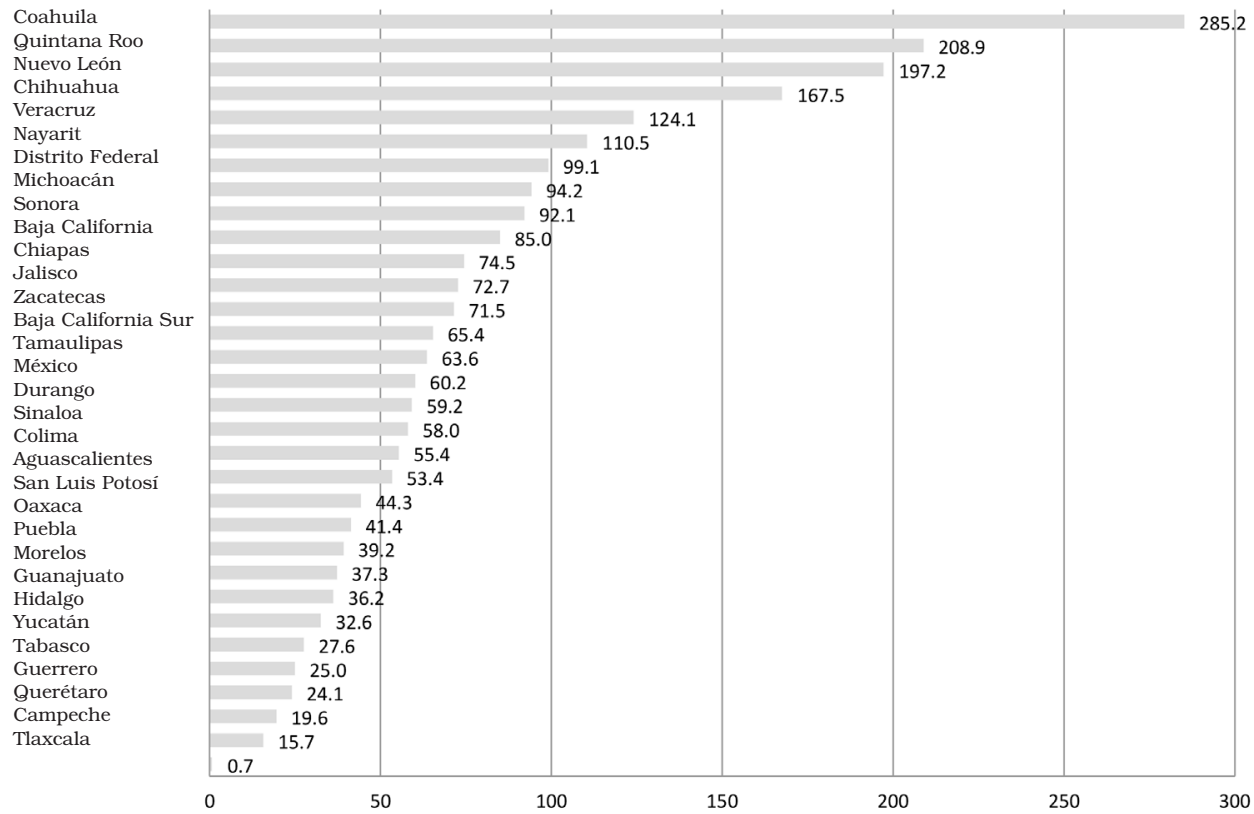

Fuente: SHCP.

Una característica adicional del endeudamiento estatal y municipal en el país es que el costo que paga cada entidad es distinto, y las entidades que tienen un menor nivel de endeudamiento no necesariamente pagan las menores tasas. Los estados a los que se les cargan mayores intereses son: Quintana Roo, Tamaulipas y Tlaxcala (este último el menos endeudado de la república). En tanto que los que reportan menores tasas son: Querétaro, Hidalgo y Puebla. 


\section{Gráfica 9 \\ Costo promedio ponderado por entidad federativa, marzo de 2013}



Fuente: SHCP.

Conviene indicar que los saldos dados a conocer por la SHCP se refieren a la deuda pública garantizada con participaciones federales que cuentan con la aprobación de los congresos locales, más otras obligaciones que opcionalmente las entidades dan a conocer a las autoridades federales, por lo que el registro de la Secretaría sólo representa parcialmente el saldo de la deuda pública de los estados (ASF, 2012). 
Entre las principales cusas que dieron origen al problema de deuda subnacional se identifican las siguientes:

- Una limitada capacidad financiera estructural de los gobiernos locales para cubrir su creciente gasto público, lo cual se manifiesta como un déficit persistente en las finanzas públicas locales.

- El efecto de la crisis económica de 2009 sobre la Recaudación Federal Participable. En ese año, la reducción en las participaciones por 47.7 mil millones de pesos fueron compensadas por un incremento del endeudamiento subnacional (49.1 mil millones de pesos) (ASF, 2012).

- Los ingresos de las entidades federativas son dependientes de recursos federales en cerca de 90\%. Adicionalmente, a partir de 2012, las haciendas locales de algunas entidades eliminaron el Impuesto Federal Sobre Tenencia y Uso de Vehículos, cuya recaudación era 100\% participable.

- El gasto público de las entidades muestra una tendencia inercial; 90\% es gasto público obligatorio (educación, salud, seguridad social, seguridad pública, pensiones, servicios personales y el paripassu de los programas federales que operan en concurrencia financiera federal y local).

- Por otro lado, en el caso del gasto irreductible en educación y salud, este se ha elevado paulatinamente en los últimos años con el proceso de descentralización. La participación estatal en la subvención de 2000 a 2011 , pasó de 27.9 a $35.8 \%$ del total.

- En el 2000 el gasto federalizado constituía en promedio 70\% del gasto educativo de las entidades federativas, mientras que para 2011 representó $63.4 \%$, por lo que el gasto de las entidades federativas en la materia pasó de 30 a 36.6\% en el mismo periodo. El crecimiento promedio real de los ingresos propios (incluidas las Participaciones Federales) ha sido $3.8 \%$, en tanto que las erogaciones de los estados para educación han crecido a una tasa de $5.2 \%$ para ese periodo (ASF, 2012).

- Como se indicó anteriormente, un factor adicional que contribuyó a elevar la deuda pública fue la disminución de las tasas de interés. Lo anterior se reflejó en el costo promedio de la deuda subnacional, que pasó de $9.6 \%$ en 2008 a $6.3 \%$ en 2010 y a $6.5 \%$ en 2012 . 
Las entidades federativas han aportado cada vez más recursos a educación y salud en comparación con el Gobierno Federal. De acuerdo con el CEFP, de 2000 a 2011, por ejemplo, la aportación al gasto de las entidades federativas en la materia aumentó de 30 a 36.6\% mientras que el gasto federalizado, disminuyó su participación de 70 a 63.4 por ciento.

\section{Gráfica 10}

\section{Aportaciones federales y estatales al gasto en educación y salud}

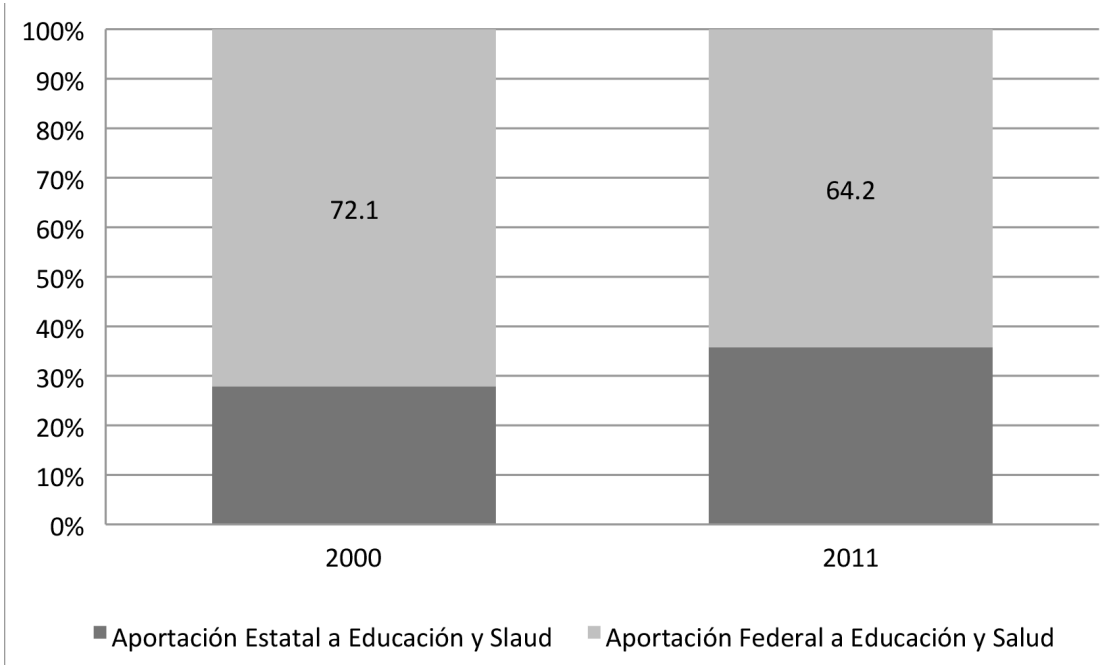

Fuente: SHCP.

De esta forma, la vulnerabilidad de los ingresos de las entidades federativas y el gasto público creciente e inercial, producen un déficit público persistente y acumulativo, lo que se traduce en un problema de carácter estructural para las finanzas públicas locales.

Reforma en materia de disciplina financiera estatal y municipal

El pasado 30 de abril, en la Cámara de Diputados se presentó una Iniciativa que Reforma y Adiciona diversas disposiciones de la Constitución Política de los Estados Unidos Mexicanos. ${ }^{1}$ Unos meses más tarde, la Comisión de Pun-

\footnotetext{
${ }^{1}$ Se trata de la Iniciativa que reforma los artículos 74, fracciones VII, VIII y IX; 79, párrafos primero y segundo de la fracción I; 108, último párrafo; 116, párrafo sexto de la fracción II y 117, fracción VIII; y se adicionan los artículos 25, con un párrafo segundo, pasando los actuales párrafos segundo a octavo a ser los párrafos tercero a noveno; 74, con las fracciones VIII y IX, de la Constitución Política de los Estados Unidos Mexicanos, suscrita por los diputados,
} 
tos Constitucionales elaboró un dictamen que fue aprobado en lo general, en la sesión del 17 de julio de 2013 en período extraordinario en la Cámara de Diputados. ${ }^{2}$

Entre los principales puntos de la exposición de motivos de la Iniciativa destacan los siguientes (CEFP, 2013):

- Se reconoce que el problema del endeudamiento estatal y municipal en el país no es nuevo, pues ya en 1995 la crisis ocasionó una elevada cartera vencida en los gobiernos locales, por lo que el Gobierno Federal implementó un programa de reestructuración a fin de que sus finanzas fueran viables.

- En la actualidad los recursos con que cuentan los gobiernos locales no son suficientes para atender las necesidades de la población, por lo que se ha hecho uso del endeudamiento para llevar a cabo proyectos sociales y de infraestructura.

- No obstante, el endeudamiento subnacional ha crecido de forma importante en los últimos años, por lo que, de acuerdo con la iniciativa, es urgente replantear el manejo de las finanzas públicas locales, haciendo un uso correcto de los recursos con el propósito de no obstaculizar las posibilidades de crecimiento y desarrollo locales.

- La reforma busca además, garantizar el uso eficiente y transparente de los empréstitos, así como fijar límites al endeudamiento estatal y municipal.

- Se reconoce también que entre los factores que han afectado la capacidad de pago de los gobiernos locales se encuentran los siguientes: un gasto corriente superior a los ingresos fiscales; una menor recaudación a la pronosticada; incrementos en las tasas de interés causados por desequilibrios macroeconómicos y elevadas tasas de

\footnotetext{
Miguel Alonso Raya del Grupo Parlamentario PRD, Jorge Iván Villalobos Seañez del Grupo Parlamentario PAN, Arturo Escobar y Vega, y Tomás Torres Mercado, del Grupo Parlamentario PVEM, María Sanjuana Cerda Franco del Grupo Parlamentario PANAL, Lilia Aguilar Gil del Grupo Parlamentario PT, Ricardo Mejía Berdeja del Grupo Parlamentario MC y Marco Antonio Bernal Gutiérrez, José Manzur Quiroga y Manuel Añorve Baños, del Grupo Parlamentario PRI, integrantes de la LXII Legislatura.

${ }^{2}$ En este caso, se refiere al proyecto de decreto por el que se reforman diversas disposiciones de la Constitución Política de los Estados Unidos Mexicanos, en materia de disciplina financiera de Estados y Municipios, por medio del cual se reforman la fracción VIII del Artículo 73; los párrafos primero y segundo de la fracción I del Artículo 79; el párrafo cuarto del Artículo 108; el párrafo sexto de la fracción II del Artículo 116; y el párrafo segundo de la fracción VIII 117; y se adicionan con un segundo párrafo; recorriéndose en su orden los subsecuentes al Artículo 25; la fracción XXIX-R al Artículo 73; la fracción VIII al Artículo 74, pasando la actual a ser fracción IX; y los párrafos tercero y cuarto fracción VIII del Artículo 117 todos de la Constitución Política de los Estados Unidos Mexicanos.
} 
inflación; así como una actitud displicente de la banca privada en el otorgamiento de créditos sin el debido análisis de la situación económica de los solicitantes.

La iniciativa intenta adecuar el marco jurídico para hacer posible un uso más eficiente, transparente y responsable de los recursos públicos en los estados y municipios, a fin de brindar certidumbre a los contribuyentes acerca del destino de dichos recursos. Por lo que basándose en el inciso $\mathrm{H}$ del Artículo 72 Constitucional $^{3}$ se hicieron las siguientes reformas (CEFP, 2013):

Artículo 25: en este artículo se incluyen principios básicos para contar con un desarrollo económico sostenible; y se prevé que el Estado (el gobierno en sus tres órdenes) vele por la estabilidad de las finanzas públicas y del sistema financiero, procure el equilibrio presupuestario y la sostenibilidad financiera, tomando en consideración los ciclos económicos nacionales e internacionales; también establece que el Plan Nacional de Desarrollo y los planes estatales y municipales deberán observar dichos principios.

Artículo 73: en lo referente a endeudamiento estatal y municipal, las modificaciones a este artículo establecen que el Congreso tiene la facultad de establecer las bases para que los tres órdenes de gobierno puedan endeudarse, así como los límites y modalidades bajo las cuales pueden afectar sus participaciones para cubrir los empréstitos y obligaciones de pago que contraigan. Además, se obliga a estados y municipios a inscribir y publicar el total de sus obligaciones de pago en un registro público único de forma oportuna y transparente. Otra de las facultades del Congreso sería el establecimiento de las sanciones aplicables a los servidores públicos que no cumplan sus disposiciones; y se aclara además que éste tipo de leyes deben discutirse de forma inicial en la Cámara de Diputados.

En cuanto a la fracción XXIX-R del mismo Artículo 73, la reforma faculta al Congreso a expedir leyes en materia de responsabilidad hacendaria, que tengan por objeto el manejo sostenible de las finanzas públicas de la federación, estados, municipios y el Distrito Federal.

Artículo 74: en lo referente a la Fracción VIII de éste Artículo, se otorga, como facultad exclusiva de la Cámara de Diputados, el conocer y opinar (a través de la Comisión legislativa correspondiente), las estrategias de ajuste para el fortalecimiento de las finanzas públicas de los estados que tengan

${ }^{3}$ El Artículo 72 inciso $\mathrm{H}$ de la constitución establece que la formación de las leyes o decretos puede comenzar indistintamente en cualquiera de las dos Cámaras, con excepción de los proyectos que versaren sobre empréstitos, contribuciones o impuestos, o sobre el reclutamiento de tropas, todos los cuales deberán discutirse primero en la Cámara de Diputados. 
convenios con el gobierno federal en materia de garantías. Asimismo, la Cámara de Diputados también tendría que ser informada de la estrategia de ajuste de los municipios que se encuentren en el mismo supuesto.

Artículo 79: en éste Artículo se establece que la Auditoría Superior de la Federación (ASF) no sólo fiscalizará los egresos, sino también la deuda y las garantías que, en su caso, otorgue el Gobierno Federal a los empréstitos de los estados y municipios. Asimismo, faculta a la ASF para conocer el destino y ejercicio de los recursos que los gobiernos locales hayan obtenido con garantía de la federación.

Artículo 108: en este caso se establece la obligación de los gobiernos locales de contemplar en sus Constituciones Estatales la responsabilidad en que incurrirían los servidores públicos por el manejo indebido de recursos públicos y de la deuda pública.

Artículo 116: este artículo contempla que las entidades federativas contaran con entidades estatales de fiscalización; lo que la reforma incorpora, es la obligación de estas entidades de fiscalizar las acciones de los gobiernos estatales y municipales en materia de fondos, recursos federales y locales, y deuda pública.

Artículo 117: las modificaciones a este artículo, pretenden dar sostenibilidad a las finanzas públicas locales al considerar los siguientes elementos (CEFP, 2013):

- Se mantiene la prohibición para contraer obligaciones en moneda extranjera con gobiernos de otras naciones.

- Precisa que el endeudamiento podrá destinarse a inversiones públicas productivas y a su refinanciamiento o reestructura bajo las mejores condiciones de mercado.

- Faculta a los gobiernos estatales a otorgar garantías a sus municipios conforme a las bases que las legislaturas locales establezcan en la legislación correspondiente y hasta por los montos que ellas mismas aprueben.

- También se establece que en ningún caso los empréstitos podrán destinarse a cubrir gasto corriente.

- Las legislaturas locales deberán aprobar, por el voto de dos terceras partes de sus miembros presentes, los empréstitos y obligaciones de su entidad. Lo anterior se haría previo estudio de su capacidad de pago, destino de los recursos, garantías y fuentes de pago. 
- Prevé la posibilidad de contratar deuda para cubrir necesidades de corto plazo sin rebasar los límites que imponga la ley general que expida el Congreso de la Unión, y siempre y cuando se liquide totalmente a más tardar tres meses antes de la conclusión del período de gobierno correspondiente. Cabe señalar que la propuesta también les impide contratar financiamientos durante esos últimos tres meses.

\section{Consideraciones finales}

Existe evidencia de que el problema de los elevados niveles de endeudamiento tiene su origen en factores estructurales de las finanzas públicas estatales y otros de origen externo, particularmente, en la crisis financiera mundial.

Las haciendas estatales se caracterizan por bajos niveles de recaudación, una alta dependencia de las Participaciones Federales y un gasto público creciente, irreductible e inercial; y la crisis de 2009 impactó significativamente la Recaudación Federal y, por tanto, las participaciones a los estados, presionándolos a contraer deuda.

Tratar de resolver el problema de deuda de las entidades federativas enfocándose sólo en la regulación del financiamiento, no soluciona el problema de fondo y simplemente hace más complejo el manejo de las finanzas públicas estatales. Lo que se requiere es una reforma integral del federalismo hacendario, que permita fortalecer los ingresos de las haciendas locales sin dejar de lado una mayor eficiencia, eficacia y transparencia en el ejercicio del gasto público.

Un aspecto importante de la reforma es que obliga a los gobiernos estatales y municipales a inscribir en un registro único el total de sus obligaciones financieras, lo cual abonaría en la transparencia del endeudamiento público estatal y municipal pues en la actualidad las entidades federativas sólo tienen la obligación de reportar los créditos obtenidos con garantía de sus participaciones federales, lo cual limita el conocimiento de su nivel de endeudamiento.

Existen, sin embargo, algunos elementos que quedaron fuera de la iniciativa propuesta y que podrían contribuir a mejorar la situación fiscal de las entidades federativas y municipios; por ejemplo, sería deseable que se exigiera que un porcentaje de la deuda local estuviera respaldado con ingresos propios; así se incentivaría la eficiencia recaudatoria en los gobiernos 
locales pues ello les permitiría acceder a una mayor cantidad de recursos.

Por otro lado, tampoco considera lo que ocurrirá con la presión que ejercen los pasivos laborales sobre el gasto corriente de las entidades federativas.

Un elemento adicional que no fue tomado en cuenta por la iniciativa fue la posible creación de fondos locales de contingencia, los cuales podrían conformarse con una proporción de los ingresos excedentes que eventualmente se entregan a los gobiernos estatales.

Así, las propuestas para regular el endeudamiento estatal probablemente permitirán que efectivamente se alcancen niveles financieramente sanos de financiamiento; sin embargo, no se soluciona el problema de fondo que es el incremento de los ingresos propios, y la elevación de la calidad del gasto.

Lo anterior no puede hacerse sin tomar en cuenta la situación actual y la opinión de quienes se verán directamente afectados por las reformas, esto es, de los estados y municipios del país.

\section{Bibliografía}

- ASF (2012), Análisis de la deuda pública de las entidades federativas y municipios, http://www.asf.gob.mx/uploads/56_Informes_especiales_de_auditoria/1._Analisis_de_Deuda_Publica_Agosto_2012.pdf

- CEFP (2013), Sobre la reforma en materia de disciplina financiera en estados y municipios.

http://www.cefp.gob.mx/publicaciones/nota/2013/julio/notacefp0472013.pdf

- $\operatorname{SHCP}$ (2013),

http://www.shcp.gob.mx/Estados/Deuda_Publica_EFM/2013/ Paginas/1erTrimestre.aspx

- Gaceta Parlamentaria (30 de abril de 2013), Iniciativa que reforma los artículos 74, fracciones VII, VIII y IX; 79, párrafos primero y segundo de la fracción I; 108, último párrafo; 116, párrafo sexto de la fracción II y 117, fracción VIII; y se adicionan los artículos 25, con un párrafo segundo, pasando los actuales párrafos segundo a octavo a ser los párrafos tercero a noveno; 74, con las fracciones VIII y IX, de la Constitución Política de los Estados Unidos Mexicanos, suscrita por los diputados, Miguel Alonso Raya del Grupo Parlamentario PRD, Jorge Iván Villalobos Seañez del Grupo Parlamentario PAN, Ar- 
turo Escobar y Vega, y Tomás Torres Mercado, del Grupo Parlamentario PVEM, María Sanjuana Cerda Franco del Grupo Parlamentario PANAL, Lilia Aguilar Gil del Grupo Parlamentario PT, Ricardo Mejía Berdeja del Grupo Parlamentario MC y Marco Antonio Bernal Gutiérrez, José Manzur Quiroga y Manuel Añorve Baños, del Grupo Parlamentario PRI, integrantes de la LXII Legislatura.

- Gaceta Parlamentaria (17 de julio de 2013), Proyecto de decreto por el que se reforman diversas disposiciones de la Constitución Política de los Estados Unidos Mexicanos, en materia de disciplina financiera de Estados y Municipios, por medio del cual se reforman la fracción VIII del Artículo 73; los párrafos primero y segundo de la fracción I del Artículo 79; el párrafo cuarto del Artículo 108; el párrafo sexto de la fracción II del Artículo 116; y el párrafo segundo de la fracción VIII 117; y se adicionan con un segundo párrafo; recorriéndose en su orden los subsecuentes al Artículo 25; la fracción XXIX-R al Artículo 73; la fracción VIII al Artículo 74, pasando la actual a ser fracción IX; y los párrafos tercero y cuarto fracción VIII del Artículo 117 todos de la Constitución Política de los Estados Unidos Mexicanos. 